\title{
Do rapidly developing countries take up new responsibilities for climate change mitigation?
}

\author{
Axel Michaelowa ${ }^{1} \cdot$ Katharina Michaelowa $^{1,2}$
}

Received: 17 August 2014 / Accepted: 6 October 2015 / Published online: 21 October 2015

(C) Springer Science+Business Media Dordrecht 2015

\begin{abstract}
A significant number of countries classified as "developing" during the negotiation of the UNFCCC in the early 1990s have experienced rapid economic growth and increase of greenhouse gas emissions since then. We assess whether governments of such countries are considering taking up responsibility for emissions mitigation in the context of the UNFCCC's principle of common but differentiated responsibility (CBDR). While an expansion of mitigation responsibility to Non-Annex I countries has been strongly opposed by overarching groups such as the G 77, we find countries such as South Africa and Indonesia that have clearly supported binding commitments. Other countries like China and Singapore oppose binding commitments but increasingly engage in domestic mitigation action. Moreover, China has pledged a significant amount of climate finance. Even in the countries of the Gulf Cooperation Council, which adamantly refuse mitigation commitments, some mitigation action seems to emerge. We thus foresee that countries will increasingly adopt differentiated positions regarding their responsibility for mitigation. This could provide new dynamics in international climate negotiations.
\end{abstract}

\section{Introduction}

The link between rapid economic development, increased greenhouse gas emissions and the redistribution of country climate change mitigation commitments has been a matter of heated debates within the UNFCCC negotiations. The scientific literature provides considerable inputs to this debate, notably a large literature on burden sharing scenarios to limit global

This article is part of a Special Issue on "Climate Justice in Interdisciplinary Research" edited by Christian Huggel, Markus Ohndorf, Dominic Roser, and Ivo Wallimann-Helmer.

Katharina Michaelowa

katja.michaelowa@pw.uzh.ch

1 Center for Comparative and International Studies (CIS), University of Zurich, Affolternstr. 56, CH-8050 Zürich, Switzerland

2 Institute of Political Science, University of Zurich, Zürich, Switzerland 
temperature increase to $2{ }^{\circ} \mathrm{C}$ (see, e.g., Winkler 2008; Höhne et al. 2014; den Elzen et al. 2013, Tavoni et al. 2013). Moreover, a number of studies propose indicators to measure country emission reduction commitments (e.g., Michaelowa 2007; Baer et al. 2008; Müller and Mahadeva 2013). Finally, a normative literature discusses the general principles underlying different burden sharing arrangements from a climate justice perspective (e.g., Moellendorf 2012; Bell 2011).

Explicitly or implicitly, most of these studies refer to the principle of "common but differentiated responsibilities" (CBDR) ${ }^{1}$ embodied in the Convention, and to the way in which this principle should be interpreted. To many observers, it appears that economically emerging countries still regarded as "developing" - and hence without binding commitments under the Kyoto-Protocol - tend to use CBDR as a justification to resist any demands for commitments on their part. Yet this perception may not be entirely true, and some differences between countries can be explored to examine potential ways out of the current stalemate within the UNFCCC negotiations.

In this paper, we examine potential signals of a change in emerging countries based on developments in their governments' own perception of their responsibilities. In doing so, we go beyond Chandler et al. (2002), who demonstrated that countries constantly opposing any mitigation commitments within the framework of the UNFCCC may still implement significant mitigation action domestically. We find countries that correspond to the picture presented by Chandler et al., but also find some first indications of a willingness to take up broader responsibility.

This paper first presents some descriptive statistics on the rapid development of production and emissions in selected countries that triggered the current political debate (Section 2). We then provide an introduction to the CBDR principle as a theoretical basis for mitigation commitments (Section 3). Section 4 empirically assesses the readiness of some emerging economies to recognize their responsibility for mitigation of global climate change, and Section 5 concludes.

\section{The rapid catch-up of emerging economies}

When the talks started for Rio 1992, only a few non-OECD countries had production and emission levels comparable to advanced economies. These were either very small countries like Singapore or some of the oil producing countries that - due to their lack of diversification and limited human development - still resembled developing countries. Using OECD membership as the dividing line between "developed" or "developing" under the UNFCCC in 1992 was hence a little disputed choice.

Over the last 20 years, however, the world has changed dramatically. Today, a number of countries categorized as "developing" under the UNFCCC in 1992, and hence listed in NonAnnex I and without binding commitments under the Kyoto-Protocol, have per-capita production levels above the OECD mean. Many others have shown rapid economic and emissions growth between 1990 and 2010 (Table 1), and belong to the upper middle- and high-income country categories (UMIC and HIC). ${ }^{2}$ Considering that not even all countries within the

\footnotetext{
${ }^{1}$ In the UNFCCC process, this principle is now referred to more comprehensively as the principle of "common but differentiated responsibilities and respective capability" (CBDRRC). However, we stick to the abridged version (CBDR), which is more commonly used.

${ }^{2}$ Countries classified as HIC have a GNI per capita $\geq$ USD 12,746; for UMIC the relevant threshold is USD 4125 (World Bank 2014).
} 
European Union make it over the threshold for HIC, this classification for countries still considered as "developing" under the UNFCCC is remarkable. In 2010 six out of the world's eight wealthiest economies were considered as "developing", with a per-capita income exceeding that of the United States.

Nobody could foresee these developments when the initial classifications of "developed" and "developing" were made at the UNFCCC in 1992 (Castro et al. 2014: 112, Levine and Aden 2008). Even in the early 2000s, experts tended to grossly underestimate the underlying economic and emissions dynamics. As an example, Chandler et al. (2002: iii) start by justifying their focus on developing country emissions with the statement that "greenhouse gas emissions from developing countries will likely surpass those from developed countries within the first half of this century". As a matter of fact, this happened in 2008, only six years after the publication of the report.

Yet even talking about these changes is currently a matter of contention. During the negotiation of the summary for policymakers of the mitigation section of the IPCC 5th Assessment Report for instance, an entire section that assessed emission trends of country groups with different income levels was deleted due to ferocious opposition from China and Saudi Arabia. However, the information remains accessible in a detailed figure of the Technical Summary, which cannot be altered by governments (see IPCC WG III (2014), p. 15).

Is this conflict so entrenched that it cannot be resolved, or is there a recognition that the iron curtain between Annex I and Non-Annex I countries cannot be maintained?

\section{CBDR as a conceptual basis for mitigation contributions}

The UNFCCC's approach to mitigation is based on the principles of equity (Art. 3.1) and common but differentiated responsibilities and respective capabilities of countries (CBDRRC, Art. 3.1). Moreover, the Convention states that developed countries should take the lead in combating climate change (Art. 3.1), and that special circumstances of developing countries causing them to bear a disproportionate or abnormal burden should be given full consideration (Art. 3.2). Policies and measures should take into account different socioeconomic contexts (Art. 3.3), while countries have a right to, and should, promote sustainable development (Art. 3.4).

We focus here on CBDR because this is the UNFCCC principle most frequently referred to in the current debate. The requirement to also consider capabilities within this principle (CBDRRC) is well understood, but the question of responsibilities needs to be settled first before one can determine the concrete implications of these responsibilities in the light of respective capabilities. In addition, our empirical case studies will cover only UMIC and HIC, so that economic and financial capabilities are ensured.

The responsibility principle reflects the polluter-pays principle. It can take the form of historic responsibility (emissions since an agreed start date), current responsibility (total emissions per year) and future responsibility (emission projections until an agreed date). As past dynamics have shown that emissions can rise substantially over a few years, the consideration of future responsibility is important when it comes to commitments for a distant year, e.g. 2050. However, as mentioned above, these dynamics are extremely difficult to predict. Levine and Aden (2008) provide an interesting account of the repeated revisions of emission forecasts for China in the past. Their study clearly demonstrates why, in practice, 
establishing responsibilities on the basis of future emissions is extremely difficult. This may be the reason why the current debate focusses on historical versus current responsibility. ${ }^{3}$

Obviously, a focus on historical emissions is in the interest of countries that have become strong emitters only recently, while a focus on current emissions shifts a greater part of the responsibility towards these countries. Similarly, the length of time to be taken into account regarding historical emissions is important. The longer it is, the less the responsibility of countries with a strong recent emissions growth. Responsibility can also be measured as emissions above a certain per capita threshold (sometimes called "luxury emissions"), to take account of basic development needs. Agreement on such a threshold requires a common understanding of the consumption level perceived as consistent with human basic needs, as well as the emissions intensity of goods and services production.

These considerations (along with the considerations of capability) have led to suggestions of diverse systems of indicators to determine commitments (for an overview, see Höhne et al. 2014; Winkler and Rajamani 2014: 110-114, or Pauw et al. 2014:13-14). Related proposals have been introduced in the negotiation process with the argument that they reflect a much more appropriate interpretation of CBDR. According to all of these proposals HICs would lose the benefits of their current status as a "developing country".

Not surprisingly, countries that might have to contribute under such a revised indexed regime have voiced their opposition to any differentiation within the group of Non-Annex I countries. They also convinced the larger group of developing countries (G77\&China) to support their perspective. Rajamani (2013: 158 f.) quotes a 2008 submission by the Philippines on behalf of this group that expresses its "firm rejection" of "any proposal directed towards differentiating between Non-Annex I parties." Supporting this perspective by interpreting CBDR essentially as the fixation of a binary differentiation between Annex I and NonAnnex I, Rajamani (2013) argues that ever since the Conference of the Parties (COP) in Bali 2007, there has been a gradual erosion of the CBDR principle because any remaining differentiation is across all countries rather than between these two groups. She observes that this trend is most clearly reflected in the formulation of the Durban Platform (adopted in 2011) that the future regime should be "applicable to all" (Rajamani 2013: $164 \mathrm{f}$.).

Where does this erosion come from? Is it simply from pressure by wealthy nations? Or is it a gradual reorientation by some former opponents of any more flexible interpretation? In any case, it shows a tentative step towards more flexibility, moving away from the fixed bi-polar understanding of the world independently of changing realities. If CBDR is taken seriously as a principle that distinguishes between actual responsibilities (rather than those projected decades ago on the basis of now outdated statistics), then linking its interpretation to appropriate indicators should be welcomed. Moreover, such a change would provide the opportunity to consider responsibilities on a continuous scale - recognizing that differences within current groups may for certain countries be larger than differences across groups.

In the following, we will not engage in a normative debate, but focus on a more detailed empirical analysis of the positions of emerging and advanced developing countries, and their governments' own perception about their responsibilities. ${ }^{4}$

\footnotetext{
${ }^{3}$ It should be noted, however, that some predictions of future emissions are necessary in order to establish the baseline scenario to assess countries' emission reductions. So far, countries have an incentive to overestimate baseline emissions because this inflates their perceived mitigation effort. If such baselines were simultaneously used to calculate responsibilities, the incentive to compute biased baselines could be significantly reduced.

${ }^{4}$ For further discussion of CBDR, also considering its use in other international treaties, see Honkonen (2009), and Pauw et al. (2014).
} 
Table 1 Economically advanced and rapidly growing non-Annex I countries

\begin{tabular}{|c|c|c|c|c|}
\hline Country & $\begin{array}{l}\text { Growth of per-capita } \\
\text { emissions } 1990-2010 \text {, in \% }\end{array}$ & $\begin{array}{l}\text { GDP growth } \\
1990-2010 \text {, in \% }\end{array}$ & $\begin{array}{l}\text { GDP per capita, } \\
\text { PPP } 2010\end{array}$ & $\begin{array}{l}\text { Income } \\
\text { category } 2010\end{array}$ \\
\hline \multicolumn{5}{|c|}{ Countries with per-capita emissions increasing by more than $100 \%$ between 1990 and 2010} \\
\hline Vietnam & 471.6 & 318.4 & 2875 & \\
\hline Oman & 274.3 & 149.4 & 24,556 & $\mathrm{HIC}$ \\
\hline Trinidad and Tobago & 240.7 & 136.3 & 23,180 & $\mathrm{HIC}$ \\
\hline Nepal & 192.0 & 138.9 & 1083 & \\
\hline Sri Lanka & 189.4 & 175.2 & 4600 & \\
\hline Bangladesh & 178.2 & 181.4 & 1488 & \\
\hline People's Rep. of China & 174.1 & 630.1 & 6818 & UMIC \\
\hline Thailand & 142.6 & 136.3 & 7672 & UMIC \\
\hline Malaysia & 136.9 & 211.0 & 13,705 & UMIC \\
\hline Lebanon & 134.1 & 215.4 & 12,617 & UMIC \\
\hline Ghana & 130.7 & 168.7 & 1478 & \\
\hline Panama & 125.9 & 203.0 & 12,638 & UMIC \\
\hline El Salvador & 125.5 & 89.0 & 5977 & \\
\hline Honduras & 117.6 & 105.8 & 3518 & \\
\hline Kuwait & 116.5 & 149.7 & 45,618 & $\mathrm{HIC}$ \\
\hline Indonesia & 115.8 & 151.7 & 3885 & \\
\hline Korea & 113.6 & 182.8 & 26,774 & HIC \\
\hline Angola & 112.5 & 208.7 & 5171 & UMIC \\
\hline Islamic Rep. of Iran & 110.9 & 138.2 & 10,954 & UMIC \\
\hline India & 109.6 & 252.0 & 3038 & \\
\hline Chinese Taipei & 106.7 & 167.2 & 32,021 & $\mathrm{HIC}$ \\
\hline \multicolumn{5}{|c|}{ Additional non-Annex I countries with GDP per capita $(\mathrm{PPP})>\mathrm{OECD}$ mean } \\
\hline Qatar & 19.7 & 526.5 & 69,790 & $\mathrm{HIC}$ \\
\hline Singapore & 31.3 & 244.5 & 52,167 & HIC \\
\hline Brunei & 53.9 & 42.9 & 45,496 & $\mathrm{HIC}$ \\
\hline Hong Kong, China & 1.9 & 119.6 & 42,580 & $\mathrm{HIC}$ \\
\hline United Arab Emirates & -30.0 & 139.3 & 42,351 & HIC \\
\hline \multicolumn{5}{|c|}{ OECD mean (for comparison) } \\
\hline OECD & -3.2 & 54.4 & 30,159 & $\mathrm{HIC}$ \\
\hline
\end{tabular}

Notes: Countries in the top panel are ordered by their increase of emissions. In the lower panel, they are ordered by their GDP per capita. GDP is measured in constant 2005 USD (PPP)

Data source: IEA (2013)

\section{Emerging economies assuming responsibility?}

While Rajamani (2013) is correct in that there has been strong opposition within the UNFCCC, there are also increasingly signs of acceptance and even of pro-active propositions and some encouraging examples of national mitigation action. Four areas may reflect these dynamics:

First, given that UNFCCC decisions require consensus, it is noticeable that formulations about the explicit participation of all countries - such as in the Durban Platform - have been adopted at all (for details, see Deleuil 2012). 
Second, the arguments of some of the poor coastal and island states based on the undeniable salience of climate change mitigation for their very existence seem to have moved some countries to reconsider their positions. Even India, traditionally known for its intransigent positions and still a relatively poor country, ${ }^{5}$ reportedly reacted when blamed by other developing countries such as Bangladesh and the Maldives for the deadlock in the international negotiation process. Jairam Ramesh, Indian Minister of Environment and Forestry from May 2009 to July 2011, referred to other developing countries' criticism when justifying his adoption of a new negotiation position at COP 15 (Copenhagen) in India's upper house of parliament (Vihma 2011: 15, Michaelowa and Michaelowa 2012: 578). More generally, there is evidence for the important role of the Alliance of Small Island States (AOSIS) in convincing other Non-Annex I countries to adopt the Durban Platform (Rajamani 2013: 164). The AOSIS position within the G77 seems to have gained momentum in recent years. At COP 18 in Doha (Qatar), even BASIC (comprising Brazil, South Africa, India, and China) agreed on a more nuanced division of countries than the simple binary divide stating that "all countries should participate in an enhanced global effort" along with the focus on CBDR (Winkler and Rajamani 2014: 107).

Third, the introduction of the possibility for all countries by COP 15 to submit propositions for "Nationally appropriate mitigation actions" (NAMAs) in the context of the Copenhagen Accord has led to a significant response. Overall, 45 Non-Annex I countries submitted NAMAs, of which 17 specified a national mitigation commitment. Out of the latter, eight are not conditional on external financial support (UNFCCC 2011). According to a review by Kartha and Erickson (2011), overall mitigation commitments by Non-Annex I countries based on these pledges even exceed the corresponding pledges by Annex I countries. While the mere submission of these propositions will not necessarily translate into effective implementation, they still demonstrate an acceptance of broader participation in climate change mitigation efforts, and hence some willingness to assume responsibility. When it became clear that the Copenhagen pledges could not become a robust basis for a future climate policy regime, in the run up to the UNFCCC conference in Paris 2015 all countries were asked to submit "Intended Nationally Determined Contributions" (INDCs). These are to define a mitigation contribution for the period after 2020. By the end of the period (Sep. 30, 2015) for the compilation defined by the UNFCCC Secretariat, 104 developing countries had submitted an INDC.

Fifth, a number of emerging and advanced developing countries have already implemented domestic mitigation action. This is true even for some of those countries that voice strong opposition to any commitments at the level of the UNFCCC (Chandler et al. 2002; Conrad 2012; Michaelowa and Michaelowa 2012). This does not necessarily reflect that they are ready to take over responsibility for the global public good. Rather, much of the policy reforms may simply reflect a reduction of local pollutants that the population is no longer willing to accept, the necessity to explore alternative forms of energy to ensure supply for growing industrial and household demand, or the attempt to support emerging industries in the renewable energy sector (Chandler et al. 2002). In some countries, however, policy reforms have been set on the agenda without clear triggers of this type, and even to the detriment of the interests of national heavy industry or other potentially relevant lobby groups. In these cases, countries send a clear signal that they are willing to take on responsibility.

\footnotetext{
${ }^{5}$ The World Bank has recently classified India as a lower-middle income country, but despite its strong recent growth period, it remains much closer to the upper threshold for low-income countries than to the lower threshold for UMIC. Table 1 shows that India's per-capita income is less than half of the Chinese.
} 
In the following, we examine individual country cases in more detail. Countries were selected on the basis of two criteria. First, we want to present cases in which the evidence for the willingness to take on some responsibility has been expressed most explicitly and without external pressure. In line with the above arguments, we do not consider the uptake of measures with strong and immediate national co-benefits as a signal of responsibility. We could identify only two cases in this category, but it is worthwhile to present them because they could become a role model for others.

Second, we examine countries for which international expectations are high due to extremely high income and/or production and emission growth as presented in Table 1. Out of these, we select the ones for which most information is available.

Our selection of case studies does not aim to be representative. Our intention is simply to reexamine the proposition that these countries are not willing to take on mitigation responsibility. If we find only some cases that take on mitigation responsibility even when it goes against their short-term national interests, this claim can be proven wrong. To the extent possible in this brief paper, we also consider the domestic political economy in the different countries, and report developments that may be related to climate policy positions and implementation.

\subsection{First independent movers: clear signals of change}

South Africa and Indonesia are the most striking cases of advanced developing countries proactively proposing mitigation targets against the interests of powerful lobbies. They are not currently under much pressure as they neither belong to the extremely rich Non-Annex I countries, nor to those with the strongest growth of production and emissions in recent years. For this reason, South Africa is not listed in Table 1 while Indonesia figures in the last third of the upper panel in this table (with $116 \%$ growth in per-capita emissions and $152 \%$ growth in GDP per capita over the last two decades).

South Africa is traditionally dominated by heavy industry such as gold mining, and its electricity production is almost exclusively based on coal. Therefore, emissions intensity of South African electricity generation is among the highest in the world. In addition, energy intensity of industrial production is high due to historically low electricity prices (Tait and Winkler 2012). Politically, full electrification of poor households was high on the agenda throughout the 1990s, and has largely been achieved. This has led to a significant increase of electricity consumption. Therefore, structurally, South Africa should be expected to oppose any pressure to participate in mitigation.

Yet, South Africa has engaged proactively in mitigation (Boyd et al. 2014). Since 2007 its government subscribed to the development of detailed scenarios for long-term mitigation. These scenarios were defined in terms of absolute emissions and, even before COP 15 in Copenhagen, already included the idea of a peak year after which emissions should gradually be reduced (Tyler 2013). While South Africa was a founding member of the BASIC group of emerging economies in Copenhagen, the South African government consistently stated that it would have to provide a mitigation contribution. It hosted COP 17 in 2011 in Durban, and the breakthrough of the Durban Platform can at least to some extent be attributed to South Africa's clever negotiation strategies that enabled the decision to agree on an international climate policy regime covering all countries by 2015. Domestically, plans for a carbon tax have been developed in detail, although fossil fuel lobbies have been able to delay its actual introduction. Likewise, support of renewable energy is progressing, albeit slowly. The formal government position on climate change adopted in the run-up to COP 17 explicitly uses the term 
"responsibility", albeit more in the context of national adaptation than in the context of international mitigation (Republic of South Africa 2011). The INDC takes up the concept of peaking emissions between 2020 and 2025 .

Indonesia is heavily dependent on deforestation to expand its palm oil industry. Moreover, it has traditionally been an exporter of fossil fuels, with a significant shift from oil to coal. Domestically, fossil fuels have been heavily subsidized, especially in the transport sector. The exhaustion of natural gas resources is leading to a shift from gas to coal in power generation. Thus, as in the case of South Africa, the Indonesian government should be expected to oppose mitigation.

Yet, the Indonesian government engaged relatively early with the Norwegian government on a large-scale initiative to reduce deforestation. Moreover, in the mid-2000s, the Yudhyono government developed national as well as provincial climate change mitigation plans. Indonesia is very active in developing NAMAs in a variety of sectors (see Purnomo et al. 2013). Despite strong public protests in the late 1990s and a subsequent resignation of the president, the government also continued reducing fossil fuel subsidies, this time buffered by a compensating unconditional transfer scheme and a special health care system for the poor that were widely communicated. The experiences of this transition, including the targeting of the compensating schemes, can be considered relatively successful (Beaton and Lontoh 2010). Subsidies were further reduced by the new 2014 government. The Indonesian INDC defines a mitigation target of $29 \%$ below BAU by 2030 which would be increased to $41 \%$ if international financing is provided.

Indonesia is a case where the government has strategically harnessed the willingness of international donors to finance various mitigation initiatives. Moreover, it learnt to remove subsidies gradually and with compensating measures so as to curb public protests.

In sum, both countries actively engaged in some domestic mitigation policies, and accepted some degree of international responsibility. Even though funding of climate change mitigation was ensured from external sources (notably in Indonesia), there is no evidence that these activities focused on local short-term benefits. Rather, in both countries, these first steps required political courage to act against vested interests (e.g. a middle class used to fuel subsidies for their cars), and are clearly oriented towards national and international long-term objectives. In line with their domestic activities, they have clearly supported commitments for advanced Non-Annex I countries within the UNFCCC (Government of South Africa 2013; Government of Indonesia 2013). If their policies serve as an orientation for other countries, this could move the international process out of its current deadlock.

\subsection{Countries in the limelight: tentative signals of change}

Among the countries facing international pressure to take up some responsibility for the mitigation of global climate change in the future, the most prominent case is undoubtedly China, since it is the world's largest emitter of $\mathrm{CO}_{2}$ in absolute terms. With a $174 \%$ increase of emissions over the period 1990-2010, and more than a doubling of emissions during 20012010 alone, it figures at the high end of countries listed in Table 1. The active participation of China is essential for any meaningful international agreement. However, China has mostly opposed any internationally binding commitments, and is known as one of the strongest defenders of the binary Annex I - Non-Annex I divide. Historically, China's heavy industry has been very important, and the power sector has been dependent on coal. Nevertheless, energy efficiency improvement has been high on the political agenda, and attracted significant 
central government investments (Conrad 2012; Chandler et al. 2002: 12-19). The renewable energy industry has expanded massively since the late 2000s and the government has declared impressive expansion targets for the future.

While these are important developments, their motivation can be traced to the requirements of the national political economy. The government is conscious that competitiveness as well as public resistance to extreme local air pollution requires reduced fossil fuel utilization. Moreover, the need to ensure energy security for its growing economy and the opportunity to gain a competitive edge in the renewables sector through the large scale of its operations appear to be important drivers of policy reform. This interpretation, together with the government's unambiguous statements against any kind of obligations at the international level, appear to indicate that China has not yet accepted to assume responsibility for global climate change.

Nevertheless, China presented a serious emissions intensity pledge at Copenhagen (Conrad 2012) that was not conditional on external financial support. Moreover, as a member of BASIC, China supposedly accepts the BASIC position on the participation of "all countries [...] in an enhanced global effort" quoted above. Finally, the US-China deal in November 2014 provided some indications of change: While the deal was relatively minimal when comparing agreed emission reductions to plausible business-as-usual scenarios, it indicated that China should finally be ready to take up some international commitments in the context of COP 21 in Paris. The INDC took up the terms of this deal. The announcement of providing 3 billion USD of climate finance made in September 2015 shows an increased willingness to engage in mitigation action worldwide and to take over significant responsibility.

The choice of other country cases is less obvious. As Table 1 includes numerous countries from the Gulf region, we decided to look at them simultaneously by examining the position of the Gulf Cooperation Council. In addition, we look at Singapore, which is in many respects very similar to an OECD economy.

The Gulf Cooperation Council (GCC) is a special group within Non-Annex I. It is composed by many wealthy countries including Qatar, which is currently the world's richest country with a GDP per capita of USD 69,790 and impressive GDP growth (see Table 1). Given their economic benefits from fossil fuel exports, they have constantly tried to block or at least slow down international mitigation efforts. At the level of the UNFCCC, several of their submissions have even included the bold request that their financial losses due to mitigation should be compensated by the international community (Luomi 2009: 4-5). With the exception of the United Arab Emirates, GCC countries did not even sign the Copenhagen Accord. In sum, this indicates a complete lack of perceived responsibility for global climate change and the consequences thereof.

A somewhat more open stance was visible in the run-up to COP 18 in Doha 2012, with four members of GCC signing up to a declaration to engage in domestic mitigation policies, though the declaration has not led to concrete policies so far. However, some interesting individual projects are underway in GCC countries, such as the construction of a carbon-neutral city (Masdar) in Abu Dhabi. Furthermore countries start realizing that without any efforts to limit energy consumption, even the ample regional energy resources at their disposal might eventually not cover domestic demand (Michaelowa et al. 2014). This economic consideration may lead to some policy reforms in the future. As shown in Table 1, the United Arab Emirates have, in fact, already achieved some emission reductions over the last two decades - at least in per-capita terms, which is important to note since population growth was very high. GCC countries did not submit INDCs by the September 2015 deadline but had started working on them. 
The situation in Singapore is very different. It is not a fuel producer and generally, its absolute emissions remain low due to its small size. Yet, it is difficult to understand why such a stable, developed economy should not provide a mitigation contribution. Singapore is the world's third most highly developed economy and simultaneously part of AOSIS and of G77. As a member of AOSIS it should be interested in pushing broad participation in global mitigation efforts. Moreover, the high share of services in its economy should make it politically rather easy for the government to adopt mitigation policies domestically. While its harbor operations are emissions-intensive, they benefit from the "bunker fuel exception" and are hence not accounted for in the national inventories. Nevertheless, on the international level, Singapore has never made any attempt to provide a mitigation contribution. It has kept a low profile, and hidden in the G 77 (Hamilton-Hart 2006; Low 2011). Initially, it did not even join the Kyoto-Protocol, although this decision was reversed in 2006. According to HamiltonHart (2006), the initiative did not reflect any normative reorientation or willingness to take up international responsibility, but rather simply seemed beneficial from a foreign policy perspective. Singapore's INDC is modest, just promising peaking of emissions by 2030 .

But again, just as in the Chinese case, the government has implemented a number of domestic policies with significant mitigation benefits. Some of these have been remarkably innovative. For example, public housing policy and expansion of public transport were linked, which led to a high share of public transport utilization (Lam and Toan 2006). Moreover, road pricing and tradable car acquisition rights make driving very expensive. According to Han (2010) Singapore's combination of investments in public transportation with well-managed policies to reduce the ownership and use of cars provides a role model for a sustainable transport system (see also Olszewski 2007). Müth and Minhans (2014) comparative study underscores that comprehensive consultation processes along with efficient administration enabled Singapore's successful implementation of these policies.

Overall, the picture is mixed, with partially contradicting policies even within countries or regions. We do not really see any clear cases in which a country takes up responsibility from climate change mitigation commitments under the UNFCCC framework. Yet, we do see certain moves towards domestic mitigation policy at least in China and Singapore, some of which are even very progressive. Many of these policies - such as the Chinese large-scale investment in renewables and the Singapore public transportation policy - are not simply oriented at shortterm gain. These developments are encouraging and may also serve as examples for other countries. In addition, if China truly comes up with a significant contribution for the Paris negotiations, this will have a major impact on the negotiation dynamics in general.

\section{Conclusions}

The above discussion shows that while a few Non-Annex I countries like the members of the GCC are still fixated on a binary divide between Annex I and Non-Annex I countries, and believe that they deserve developing country treatment on this basis, other, considerably less wealthy countries like South Africa and Indonesia clearly indicate their willingness to take up international responsibility. Other countries like China or Singapore, which implement considerable domestic reforms but only reluctantly take up international commitments, can be situated somewhere in between.

The change towards greater flexibility is also reflected in individual statements and submissions as well as in the formulation of the Durban Platform. This interpretation is not 
only in line with the assessment of other observers of the climate negotiation process (e.g., Winkler and Rajamani 2014; Deleuil 2012), but also with the recent move of the Green Climate Fund calling for financial contributions not only by developed but also by developing countries (King 2014). A majority of developing countries has submitted INDCs, but their degree of stringency varies substantially.

Given that the rigid Annex I versus Non-Annex I divide has increasingly proven to impede future agreements (Castro et al. 2014), these new dynamics may lay the ground for more fruitful negotiations in the future.

\section{References}

Baer P, Athanasiou T, Kartha S (2008) The Greenhouse development rights framework: The right to development in a climate constrained world. EcoEquity and Christian Aid, Berkeley

Beaton C, Lontoh L (2010) Lessons learned from Indonesia's attempts to reform fossil-fuel subsidies. International Institute for Sustainable Development (IISD), Geneva

Bell D (2011) Global climate justice, historic emissions, and excusable ignorance. Monist 94:391-411

Boyd A, Coetzee K, Boulle M (2014) What does the current NAMA-space in South Africa look like? A TERI-NFA NAMA Country Report on South Africa. University of Cape Town, Energy Research Centre

Castro P, Hörnlein L, Michaelowa K (2014) Constructed peer groups and path dependence in international organizations: The case of the international climate change negotiations. Glob Environ Chang 25:109-120

Chandler W, Schaeffer R, Zhou D, Shukla PR, Tudela F, Davidson O, Alpan-Atamer S (2002) Climate change mitigation in developing countries: Brazil, China, India, Mexico, South Africa, and Turkey. Pew Center on Global Climate Change, Washington

Conrad B (2012) China in Copenhagen: Reconciling the "Beijing Climate Revolution" and the "Copenhagen Climate Obstinacy". The China Q 210:435-455

Deleuil T (2012) The common but differentiated responsibilities principle: changes in continuity after the Durban Conference of the Parties. RECIEL 21:271-281

den Elzen M, Hof A, Mendoza Beltran A, van Ruijven B, van Vliet J (2013) Implications of long-term global and developed country reduction targets for developing countries. Mitig Adapt Strateg Glob Chang 18:491-512

Government of Indonesia (2013) Submission by the Republic of Indonesia https://unfccc.int/files/documentation/ submissions_from_parties/adp/application/pdf/adp_indonesia_workstream_1_20130308.pdf. Accessed 15 March 2015

Government of South Africa (2013) South African submission on mitigation https://unfccc.int/files/ documentation/submissions_from_parties/adp/application/pdf/adp_south_africa_workstream_1 mitigation 20130930.pdf. Accessed 15 March 2015

Hamilton-Hart N (2006) Singapore's Climate Change Policy: The Limits of Learning. Contemp South-East Asia 28:363-384

Han SS (2010) Managing motorization in sustainable transport planning: the Singapore experience. J Transp Geogr 18(2):314-331

Höhne N, den Elzen M, Escalante D (2014) Regional GHG reduction targets based on effort sharing: a comparison of studies. Clim Pol 14:122-147

Honkonen T (2009) The common but differentiated responsibility principle in multilateral environmental agreements: regulatory and policy aspects. Kluwer, New York

IEA (2013) $\mathrm{CO}_{2}$ emissions from fossil fuel combustion 1971-2011, Paris

IPCC WG III (2014) Technical Summary, Working Group III contribution to the IPCC Fifth Assessment Report (AR5) Climate Change 2014: Mitigation of climate change, Geneva

Kartha S, Erickson P (2011) Comparison of Annex 1 and non-Annex 1 pledges under the Cancun Agreements. SEI Working Paper WP-US-1107. Stockholm

King E (2014) Green Climate Fund wants developing country cash. Global Climate Change News and Analysis (ed 28 July). http://www.rtcc.org/2014/07/28/green-climate-fund-wants-developing-country-cash. Accessed 11 August 2014

Lam S, Toan T (2006) Land transport policy and public transport in Singapore. Transportation 33(2):171-188

Levine M, Aden NT (2008) Global carbon emissions in the coming decades: the case of China. Report LBNL372E. Ernest Orlando Lawrence Berkeley National Laboratory 
Low M (2011) Singapore's role in the UNFCCC Green Climate Fund Eco Business. http://wwwecobusinesscom/opinion/singapores-role-in-the-unfccc-green-climate-fund-by-melissa-low/ Accessed 11 August 2014

Luomi M (2009) Bargaining in the Saudi Bazaar. Common ground for a post-2012 climate agreement?, Finnish Institute of Foreign Affairs Briefing Paper 48, Helsinki

Michaelowa A (2007) Graduation and deepening. In: Aldy J, Stavins R (eds) Architectures for agreement. Cambridge University Press, Cambridge, pp. 81-104

Michaelowa K, Michaelowa A (2012) India as an emerging power in international climate negotiations. Clim Pol 12:575-590

Michaelowa A, Honegger M, Eschmann M, Dransfeld B, Krey M (2014) The role of CDM and NAMAs to promote greenhouse gas reductions in the GCC. In: Ferroukhi R, Luciani G (eds) Political Economy of Energy Reform: the Clean Energy-Fossil Fuel Balance in the Gulf States. Gerlach Press, Berlin, pp. 143-182

Moellendorf D (2012) Climate change and global justice. WIREs Clim Chang 3:131-143

Müller B, Mahadeva M (2013) The Oxford Approach. Operationalizing the UNFCCC Principle of 'Respective Capabilities'. EV 58. Oxford Institute for Energy Studies, Oxford

Müth M, Minhans A (2014) A comparative review of the making of urban transport policies in metropolitan areas in Southeast Asia. Jurnal Teknologi 70(4): 83-90

Olszewski P (2007) Singapore motorisation restraint and its implications on travel behaviour and urban sustainability. Transportation 34:319-335

Pauw P, Bauer S, Richerzhagen C, Brandi C, Schmole H (2014) Different perspectives on differentiated responsibilities: a state-of-the-art review of the notion of common but differentiated responsibilities in international negotiations. DIE Discussion Paper 6/2014. German Development Institute, Bonn.

Purnomo A, Katili-Niode A, Melisa E, helmy F, Sukadri D, Sitorus S (2013) Evolution of Indonesia's climate change policy. From Bali to Durban. National Council on Climate Change, Jakarta

Rajamani L (2013) Differentiation in the emerging climate regime. Theor Inquiries Law 14:151-171

Republic of South Africa (2011): Climate change awareness campaign. Department of Environmental Affairs. http://www.climateaction.org.za/cop17-cmp7/sa-government-position-on-climate-change. Accessed 11 August 2014

Tait L, Winkler H (2012) Estimating greenhouse gas emissions associated with achieving universal access to electricity in South Africa. University of Cape Town, Energy Research Centre

Tavoni M, Kriegler E, Aboumahboub T, Calvin K, de Maere G, Jewell J, Kober T, Lucas P, Luderer G, McCollum D, Marangoni G, Riahi K, van Vuuren D (2013) The distribution of the major economies' effort in the Durban platform scenarios. Limits Special Issue, Milan

Tyler E (2013) South Africa: A case study on national and sub-national climate policy experiences. Discussion note prepared for workshop on "Building the hinge: Reinforcing national and global climate governance mechanisms", 5-7 December 2013, Alwar

UNFCCC (2011) Compilation of information on nationally appropriate mitigation actions to be implemented by Parties not included in Annex I to the Convention: Note by the secretariat. FCCC/AWGLCA/2011/INF.1, Bonn

Vihma A (2011) India and the global climate governance: between principles and pragmatism. Environ Dev 20: $1-26$

Winkler H (2008) Climate change mitigation negotiations, with an emphasis on options for developing countries. University of Cape Town, Energy Research Centre

Winkler H, Rajamani L (2014) CBDR\&RC in a regime applicable to all. Clim Pol 14:102-121

World Bank (2014) Country and lending groups. http://data.worldbank.org/about/country-and-lending-groups. Accessed 9 August 2014 